\title{
Clinical Profiles, Congenital Heart Disease, and Other Comorbidities Among Egyptian Children with Down Syndrome: A Tertiary Center Study
}

\author{
Radwa Ezzat Amin'10 Iman Ehsan Abdel-Meguid ${ }^{1}$ \\ Dina El-Tabie ${ }^{2}$ Hala Ahmed El-Gindy ${ }^{1}$

\footnotetext{
${ }^{1}$ Department of Pediatrics, Faculty of Medicine, Cairo University, Cairo, Egypt

2 Department of Psychiatry, Faculty of Medicine, Cairo University, Cairo, Egypt
}

J Child Sci 2021;11:e233-e239.
Nihal Mohamed El-Refaie ${ }^{1}$ Walaa Fakher ${ }^{2}$

Address for correspondence Radwa Ezzat Amin, MD, Department of Pediatrics, Faculty of Medicine, Cairo University, Cairo 11451, Egypt (e-mail: radwa.ezzat.amin@gmail.com).

\begin{abstract}
Keywords

- Down syndrome

- congenital heart disease

- dysmorphic features

- comorbidities

Introduction Down syndrome (DS) is the most common chromosomal disorder. It is accompanied by several comorbidities, which could lead to severe morbidity and mortality. Congenital heart disease (CHD) is one of the most commonly described condition.

Objective This study aimed to determine clinical profiles, dysmorphic features, CHD, and DS associated comorbidities in a tertiary center (Cairo, Egypt).

Patients and Methods This descriptive study included 290 patients diagnosed with DS, who presented to the Clinical Genetics clinic, Cairo University Children Hospitals, from February 2018 to December 2019. The patients' ages ranged from 2 to 4 years old. All patients were evaluated by full history, clinical examination, anthropometric measurements, and assessment of developmental milestones. Patients' diagnostic investigations including karyotype, thyroid function, and echocardiography were checked.

Results The study population consisted of 290 children with DS of which 196 (67.6\%) were male, 115 (40\%) had CHD, the most prevalent atrial septal defect (ASD), patent ductus arteriosus (PDA), and ventricular septal defect (VSD) accounting for 10.7, 7.1, and $4.2 \%$, respectively. Common dysmorphic features were upward slanting palpebral fissures (98.6\%), hypertelorism (97.9\%), and sandal gap (60.7\%). Thyroid dysfunction was the second prevalent comorbidity, found in 35 patients (12.1\%). Global developmental delay was reported affecting language (99\%), motor (94.8\%), and social (92.8\%) domains.

Conclusion The prevalence of CHD among children with DS was $40 \%$ with ASD, PDA, and VSD being the commonest. Thyroid dysfunction was the second most common comorbidity. The most prevalent dysmorphic features were upward slanting palpebral fissures, hypertelorism, and sandal gap. Developmental delay was very common, language being the most affected domain.
\end{abstract}

received

December 19, 2020 accepted after revision July 25, 2021
DOI https://doi.org/

$10.1055 / \mathrm{s}-0041-1735537$. ISSN 2474-5871. (c) 2021. The Author(s).

This is an open access article published by Thieme under the terms of the Creative Commons Attribution License, permitting unrestricted use, distribution, and reproduction so long as the original work is properly cited. (https://creativecommons.org/licenses/by/4.0/)

Georg Thieme Verlag KG, Rüdigerstraße 14, 70469 Stuttgart, Germany 


\section{Introduction}

Down syndrome (DS) is the most frequent genetic disorder causing intellectual disabilities. ${ }^{1}$ DS incidence is estimated accordingly around $1 / 750$ to 800 livebirths $^{2}$ globally. In Middle East, previous studies reported higher DS prevalence, 18/10,000 live births (Libya), 20 (Qatar), 25.9 (Oman), 23 (Saudi Arabia), 29 (Kuwait), and 31 (Dubai). ${ }^{3}$ Data from Egypt vary from 1 in 555 to 1 in $770 .^{4}$

The risk of DS significantly increases with advancing maternal age, but also paternal age may play a role..$^{5}$ Other rare identified risk factors are heredity, affecting approximately $1 \%$ of all cases of DS. ${ }^{6}$ Shalaby et al ${ }^{7}$ reported other risk factors as consanguinity, residence (rural/urban) of the family, drugs/chemicals exposure, parental educational level, paternal habits, antenatal scanning, and number of family members.

Children with DS are at increased risk for several different comorbidities such as intellectual and developmental disabilities. DS affects multiple systems in both structural and functional ways. One of the most commonly reported comorbidity is congenital heart disease, affecting approximately $50 \%$ of DS babies. ${ }^{8}$ The commonest patterns of CHD in DS were common atrioventricular canal (CAVC), VSD, and ASD, in approximately 42,22 , and $16 \%$ of $\mathrm{CHD}$, respectively. ${ }^{8}$ Most CHD is diagnosed in early childhood: $74 \%$ diagnosed in infancy and $18 \%$ from 1 to 4 years. ${ }^{3}$

Respiratory disease contributes greatly to morbidity and mortality, accounting approximately 43 to $78 \%$ of ICU admissions and $50 \%$ of patients in need of mechanical ventilation. ${ }^{9}$ Other comorbidities are leukemia, gastrointestinal diseases, visual/hearing impairments, dental issues, thyroid diseases, obstructed sleep apnea, epilepsy, and Alzheimer's diseases. ${ }^{6}$ There is also an increased prevalence of otolaryngologic morbidities, periodontal diseases, obesity ${ }_{1}{ }^{10}$ male infertility, ${ }^{11}$ and behavioral and psychological problems. ${ }^{12}$ Children with DS are more vulnerable to autoinflammatory disease as celiac, thyroiditis, and alopecia due to chronic immunological deregulation. ${ }^{13}$

\section{Objectives}

Our aim was to determine clinical profiles, frequencies of different dysmorphic features, CHD patterns, and DS comorbidities at Cairo University Children's Hospital, Egypt.

\section{Patients and Methods}

This descriptive study included 290 patients diagnosed as DS, cared for regular follow-up to the Clinical Genetics Clinic, Cairo University Children's Hospital. Data were collected starting from February 2018 to December 2019. The patients' ages ranged from 2 to 4 years old.

All patients were evaluated by full history including personal data: age, sex, residence, age of the parents at conception, prenatal screening, and socioeconomic status using socioeconomic status scale for health research. ${ }^{14}$

Clinical examination included general examination and anthropometric measurements: weight, age, and head circumference in relation to age plotted on growth charts for DS ${ }^{15}$ and CDC growth charts. ${ }^{16}$ Motor, social, and language development were evaluated by using data from a table of emerging patterns of behaviors from 1 to 5 years adapted from Nelson Textbook of Pediatrics, 20th edition. ${ }^{17}$

Patients' diagnostic investigations including karyotype, thyroid function, and echocardiography were collected by checking patients' files, follow-up echo or performing new ones at time of examination. Median age at echo was 13 months (3-25 months). Thyroid dysfunction was considered if tetraiodothyronine and/or thyroid stimulating hormones serum levels became abnormal as preliminary test and confirmed at follow-up.

\section{Statistical Analysis}

Data were analyzed by using SPSS program 25 (IBM Corp., Armonk, NY), using mean, frequency (count), and relative frequency (\%) for categorical data.

\section{Results}

A total of 290 children were recruited of which 196 (67.6\%) were males, 133 (45.9\%) were living in rural areas, and socioeconomic status of the family was low in the majority 148 (51\%); other sociodemographic data of patients with DS are shown in - Table 1.

Regarding maternal age at conception, the mean \pm SD was $35.52 \pm 7.44$ years and the median (interquartile range [IQR]) was 37 (18-50) years; mean paternal age at conception \pm SD was $42.28 \pm 8.79$ years, and the median (IQR) was 42 (23-65) years. In this study, $163(56.2 \%)$ mothers were $>35$ years old, while 208 (71.7\%) of fathers were $>35$ years old. The prenatal screening in the form of history of ultrasound scan in any trimester was given by 279 (96\%) mothers, and positive for DS in only 7 out of 290 (2.4\%). Among children with DS, karyotyping was nondisjunction type in 283 (97.6\%), translocation in 4 (1.4\%), and mosaic in $3(1 \%)$. Different dysmorphic features were studied, and the results are shown in -Table 2. It is to be noted that each dysmorphic feature was not present alone, but in combination with other features in all patients included in the study.

History, clinical examination, and review of investigations and diagnostic studies revealed several comorbidities associated with DS as shown in - Table 3. CHD was the highest, found in 115 (40\%), followed by thyroid dysfunction in 35 (12.1\%). Single anomalies were more prevalent than combined CHD, represented by 78 patients (27\%). Considering individual CHD, the most prevalent were ASD, PDA, and VSD in $10.7,7.1$, and $4.2 \%$ respectively. Other patterns of CHD are shown in - Table 4 . It is to be noted that 37 patients (12.8\%) required CHD surgical correction.

History of previous hospitalization was found in 164 (56.6\%) of DS patients. Among all 290 patients included in the study, respiratory infections represented the majority of causes of hospitalization 102 (35.2\%), which followed by surgical causes $21(7.2 \%)$, gastroenteritis $15(5.2 \%)$, sepsis $10(3.4 \%)$, cardiac $11(3.8 \%)$, and others 5 (1.7\%). History of 
Table 1 Sociodemographic data of children with Down syndrome

\begin{tabular}{|c|c|c|c|}
\hline & & Count & $\%$ \\
\hline Age & Ranges from 2-4 y & 290 & 100 \\
\hline \multirow[t]{2}{*}{ Sex } & Males & 196 & 67.6 \\
\hline & Females & 94 & 32.4 \\
\hline \multirow[t]{3}{*}{ Residence } & Urban areas & 35 & $12.1 \%$ \\
\hline & Rural areas & 133 & $45.9 \%$ \\
\hline & Semi-urban & 122 & $42.1 \%$ \\
\hline \multirow{4}{*}{$\begin{array}{l}\text { Socioeconomic } \\
\text { status }\end{array}$} & Very low & 74 & $25.5 \%$ \\
\hline & Low & 148 & $51.0 \%$ \\
\hline & Middle & 68 & $23.4 \%$ \\
\hline & High & 0 & $0.0 \%$ \\
\hline \multirow{7}{*}{$\begin{array}{l}\text { Paternal } \\
\text { education }\end{array}$} & Illiterate & 81 & $27.9 \%$ \\
\hline & Read and write & 24 & $8.3 \%$ \\
\hline & Primary & 17 & $5.9 \%$ \\
\hline & Preparatory & 28 & $9.7 \%$ \\
\hline & Secondary & 6 & $2.1 \%$ \\
\hline & Intermediate institute & 103 & $35.5 \%$ \\
\hline & University graduate & 31 & $10.7 \%$ \\
\hline \multirow{7}{*}{$\begin{array}{l}\text { Maternal } \\
\text { education }\end{array}$} & Illiterate & 88 & $30.3 \%$ \\
\hline & Read and write & 22 & $7.6 \%$ \\
\hline & Primary & 26 & $9.0 \%$ \\
\hline & Preparatory & 32 & $11.0 \%$ \\
\hline & Secondary & 12 & $4.1 \%$ \\
\hline & Intermediate Institute & 83 & $28.6 \%$ \\
\hline & University graduate & 27 & $9.3 \%$ \\
\hline
\end{tabular}

Table 2 Dysmorphic features among patients with Down syndrome

\begin{tabular}{|l|l|l|}
\hline Dysmorphology & Count $(\boldsymbol{n}=\mathbf{2 9 0})$ & $\%$ \\
\hline Upward slanted palpebral fissure & 286 & 98.6 \\
\hline Hypertelorism & 284 & 97.9 \\
\hline Sandal gap & 176 & 60.7 \\
\hline Transverse palmar crease & 159 & 54.8 \\
\hline Protruded tongue & 148 & 51.0 \\
\hline Clinodactyly & 119 & 41.0 \\
\hline
\end{tabular}

ICU/NICU admissions was given by 126 (43.4\%). Out of all DS patients, respiratory causes of ICU/NICU admissions represented the majority $35(12.1 \%)$ as well, which followed by neonatal jaundice 32 (11\%), surgical causes 22 (7.6\%), cardiac 14 (4.8\%), prematurity $13(4.5 \%)$, sepsis 5 (1.7\%), and GIT causes $5(1.7 \%)$.

In this study, language was the most affected domain, found in 287 (99\%) of DS patients. Regarding nutritional assessment 77 (26.6\%) were underweight, only 2 (0.7\%) was overweight, and 211 (72.8\%) had normal weight for age on plotting weight on DS growth charts. In total, 43 (14.8\%) were stunted, 247 (85.2\%) attained normal height for age, and 27 (9.3\%) were microcephalic by plotting measures on DS growth charts. - Table 5 shows other domains on developmental assessment and anthropometric measures on CDC growth charts versus DS charts.

Table 3 Down syndrome associated comorbidities

\begin{tabular}{|c|c|c|c|c|c|}
\hline \multirow[t]{2}{*}{ Comorbidities } & \multirow[t]{2}{*}{$\begin{array}{l}\text { Count } \\
(n=290)\end{array}$} & \multirow[t]{2}{*}{$\%$} & \multicolumn{3}{|c|}{$\begin{array}{l}\text { Analysis whether each comorbidity was present } \\
\text { overlapping with other comorbidities or not }\end{array}$} \\
\hline & & & & Count $(n=290)$ & $\%$ \\
\hline \multirow[t]{2}{*}{ Congenital heart diseases } & \multirow[t]{2}{*}{115} & \multirow[t]{2}{*}{40} & Overlapping & 29 & 10 \\
\hline & & & Not & 86 & 30 \\
\hline \multirow[t]{2}{*}{ Thyroid dysfunction } & \multirow[t]{2}{*}{35} & \multirow[t]{2}{*}{12.1} & Overlapping & 7 & 2.4 \\
\hline & & & Not & 28 & 9.7 \\
\hline \multirow[t]{2}{*}{ Epilepsy } & \multirow[t]{2}{*}{6} & \multirow[t]{2}{*}{2.1} & Overlapping & 2 & 0.7 \\
\hline & & & Not & 4 & 1.4 \\
\hline \multirow[t]{2}{*}{ Nephrological and urogenital } & \multirow[t]{2}{*}{7} & \multirow[t]{2}{*}{2.4} & Overlapping & 3 & 1 \\
\hline & & & Not & 4 & 1.4 \\
\hline \multirow{2}{*}{$\begin{array}{l}\text { GIT (duodenal atresia, imperforate } \\
\text { anus, intestinal obstruction, Hirschsprung) }\end{array}$} & \multirow[t]{2}{*}{8} & \multirow[t]{2}{*}{2.8} & Overlapping & 2 & 0.7 \\
\hline & & & Not & 6 & 2.1 \\
\hline \multirow[t]{2}{*}{ Bronchial asthma } & \multirow[t]{2}{*}{5} & \multirow[t]{2}{*}{1.7} & Overlapping & 1 & 0.3 \\
\hline & & & Not & 4 & 1.4 \\
\hline \multirow[t]{2}{*}{ Ophthalmological } & \multirow[t]{2}{*}{6} & \multirow[t]{2}{*}{2.1} & Overlapping & 2 & 0.7 \\
\hline & & & Not & 4 & 1.4 \\
\hline \multirow[t]{2}{*}{ Otorhinolaryngological } & \multirow[t]{2}{*}{8} & \multirow[t]{2}{*}{2.8} & overlapping & 0 & 0 \\
\hline & & & Not & 8 & 2.8 \\
\hline \multirow{2}{*}{$\begin{array}{l}\text { Surgical (hernia, congenital } \\
\text { diaphragmatic hernia, } \\
\text { undescended testis, cleft palate) }\end{array}$} & \multirow[t]{2}{*}{7} & \multirow[t]{2}{*}{2.4} & Overlapping & 2 & 0.7 \\
\hline & & & Not & 5 & 1.7 \\
\hline
\end{tabular}

Abbreviation: GIT, gastrointestinal tract. 
Table 4 Congenital heart disease in Down syndrome

\begin{tabular}{|c|c|c|c|}
\hline & & $\begin{array}{l}\text { Count } \\
(n=290)\end{array}$ & $\%$ \\
\hline \multicolumn{2}{|c|}{ Total patients with CHD } & 115 & 40 \\
\hline \multirow{8}{*}{$\begin{array}{l}\text { Single } \\
\text { anomaly }\end{array}$} & Total & 78 & 27 \\
\hline & ASD & 31 & 10.7 \\
\hline & PDA & 21 & 7.2 \\
\hline & VSD & 12 & 4.1 \\
\hline & CAVC & 10 & 3.4 \\
\hline & TOF & 2 & 0.7 \\
\hline & MVP & 1 & 0.3 \\
\hline & TR & 1 & 0.3 \\
\hline \multirow{12}{*}{$\begin{array}{l}\text { Two } \\
\text { combinations }\end{array}$} & Total & 26 & 9 \\
\hline & $\mathrm{ASD}+\mathrm{PDA}$ & 9 & 3.1 \\
\hline & VSD + ASD & 5 & 1.7 \\
\hline & $\mathrm{ASD}+\mathrm{TR}$ & 2 & 0.7 \\
\hline & $C A V C+M R$ & 2 & 0.7 \\
\hline & VSD + PDA & 2 & 0.7 \\
\hline & PS + DORV & 1 & 0.3 \\
\hline & $A S D+P S$ & 1 & 0.3 \\
\hline & CAVC + PDA & 1 & 0.3 \\
\hline & VSD + PDA & 1 & 0.3 \\
\hline & VSD $+\mathrm{TR}$ & 1 & 0.3 \\
\hline & ASD + PDA & 1 & 0.3 \\
\hline \multirow{3}{*}{$\begin{array}{l}\text { Three } \\
\text { combinations }\end{array}$} & Total & 2 & 0.7 \\
\hline & $\mathrm{ASD}+\mathrm{TR}+\mathrm{PDA}$ & 1 & 0.3 \\
\hline & $\mathrm{TR}+\mathrm{MR}+\mathrm{MVP}$ & 1 & 0.3 \\
\hline $\begin{array}{l}\text { Dropped } \\
\text { patients }\end{array}$ & $\begin{array}{l}\text { Known cardiac } \\
\text { but missed Echo }\end{array}$ & 9 & 3.1 \\
\hline
\end{tabular}

Abbreviations: ASD, atrial septal defect; CAVC, common atrioventricular canal; DORV, double outlet right ventricle; MR, mitral regurge; MVP, mitral valve prolapsed; PDA, patent ductus arteriosus; PS, pulmonary stenosis; TR, tricuspid regurge; VSD, ventricular septal defect.

\section{Discussion}

In the current study, $45.9 \%$ of children with DS were born in rural areas, a higher prevalence compared with urban and semi-urban areas. This was in agreement with a study by Shalaby ${ }^{7}$ in Egypt, who reported that more DS cases were born in rural than urban areas. Many studies found a strong correlation between mother educational level and DS. ${ }^{18,19}$ In the present study, the majority of DS mothers (30.3\%) were illiterate, and this might explain the low rate of prenatal screening in this study. It was in the form of ultrasound scan only, and was positive for DS in 7 out of 290 (2.4\%). This was in agreement with Shalaby ${ }^{7}$ who found that although more mothers of DS had antenatal scan than controls, defects were not observed where antenatal scan was done to screen gross anomalies.

It is evident that advanced mothers' ages influence DS, but few data are available on genetic consequences of fathers' ages. A paternal age effect on DS is controversial. ${ }^{20}$ In our study, mean maternal age was 35.52 , and $56.2 \%$ of mothers were $>35$ years at conception. With regard to paternal age, mean age was 41.28 , and $71.7 \%$ of them were $>35$ years at conception. According to a recent systematic review, advanced paternal age is associated with mild increase in DS incidence. ${ }^{21}$ Increasing paternal age when combined with maternal age influences DS incidence. ${ }^{22}$ However, Thompson $^{23}$ reported that advanced paternal age was not associated with increasing DS or other chromosomal disorders.

General knowledge about DS clinical features by clinicians is necessary for early diagnosis. Among dysmorphic features studied, upward slanting palpebral fissures were the most frequently observed (98.6\%), in agreement with a study by Kava et $\mathrm{al}^{24}$ and by Azman et $\mathrm{al}^{25}$ Sandal gap and hypertelorism were observed in more than $40 \%$ of cases, in agreement with these studies as well. However, other clinical features such as protruding tongue and clinodactyly were noted in 51 and $41 \%$ respectively in our study, much higher than previously reported.

Karyotyping is important for clinical diagnosis confirmation, recurrence risk calculation, and genetic counseling. ${ }^{25}$ In the current study, nondisjunction was present in $97.6 \%$, translocation in $1.4 \%$, and mosaic in $1 \%$. This was in agreement with several studies that reported nondisjunction in the majority (>90\%) of DS cases, and the frequency of translocation was higher than mosaic type. $24,26,27$ However, other studies ${ }^{25,28}$ reported that mosaic type was higher than translocation type. It is to be noted that no specific reasons might explain discrepancy in DS karyotyping pattern frequency, and that difference in time periods, maternal ages, samples size, and population were considered as contributing factors. ${ }^{25}$

Neurodevelopment is delayed in DS compared with nonDS children. In our study in particular, language skills were delayed in $99 \%$ in of DS, whereas motor development was delayed in $94.8 \%$, and cognitive development was delayed in $92.8 \%$, in agreement with previous studies. ${ }^{29,30}$

Children with DS have increased frequency of respiratory tract infections and acute respiratory distress syndrome. In children $<3$ years old with DS, respiratory illnesses were the most frequent cause of hospital admissions. ${ }^{9}$ In our study, hospital admissions due to respiratory infections were the highest cause of hospitalizations and among the most frequent causes of ICU admissions with prevalence rates 35.2 and $12.1 \%$ of the total study population, respectively.

Infections deteriorate the nutritional status, and malnutrition leads to increasing infection susceptibility resulting in malnutrition infection cycle. ${ }^{31}$ In our study, $85.2 \%$ attained normal height for age when compared with DS growth charts. However, the majority (65.2\%) were stunted when plotted on CDC growth charts. Osaili et $\mathrm{al}^{32}$ found that $87.5 \%$ of studied cases attained normal heights in relation to special growth charts for DS, and 6.2\% were short for their age. On the contrary, height for age of the majority (61.2\%) of DS in their study fell 
Table 5 Growth and developmental assessment in Down syndrome

\begin{tabular}{|c|c|c|c|c|c|}
\hline \multicolumn{2}{|c|}{ Developmental assessment } & \multicolumn{2}{|l|}{ Count $(n=290)$} & \multicolumn{2}{|l|}{$\%$} \\
\hline \multirow[t]{2}{*}{ Motor } & Delayed & \multicolumn{2}{|l|}{275} & \multicolumn{2}{|l|}{94.8} \\
\hline & Normal & \multicolumn{2}{|l|}{15} & \multicolumn{2}{|l|}{5.2} \\
\hline \multirow[t]{2}{*}{ Language } & Delayed & \multicolumn{2}{|l|}{287} & \multicolumn{2}{|l|}{99} \\
\hline & Normal & \multicolumn{2}{|l|}{3} & \multicolumn{2}{|l|}{1} \\
\hline \multirow[t]{2}{*}{ Social } & Delayed & \multicolumn{2}{|l|}{269} & \multicolumn{2}{|l|}{92.8} \\
\hline & Normal & \multicolumn{2}{|l|}{21} & \multicolumn{2}{|l|}{7.2} \\
\hline \multicolumn{6}{|c|}{ Growth assessment } \\
\hline & & \multicolumn{2}{|c|}{ CDC growth charts } & \multicolumn{2}{|l|}{ DS growth charts } \\
\hline & & Count $(n=290)$ & $\%$ & Count $(n=290)$ & $\%$ \\
\hline \multirow[t]{3}{*}{ Weight } & Underweight & 101 & 34.8 & 77 & 26.6 \\
\hline & Normal & 187 & 64.5 & 211 & 72.8 \\
\hline & Overweight & 2 & 0.7 & 2 & 0.7 \\
\hline \multirow[t]{3}{*}{ Height } & Tall for age & 0 & 0 & 0 & 0 \\
\hline & Normal & 34.8 & 34.8 & 247 & 85.2 \\
\hline & Short stature & 65.2 & 65.2 & 43 & 14.2 \\
\hline \multirow{2}{*}{$\begin{array}{l}\text { Head } \\
\text { circumference }\end{array}$} & Normal & 253 & 87.2 & 263 & 90.7 \\
\hline & Microcephaly & 37 & 12.8 & 27 & 9.3 \\
\hline
\end{tabular}

Abbreviations: CDC, Centers for Disease Control; DS, Down syndrome.

short in stature for age in relation to growth charts for typical children. This shows the importance to use DS growth charts when comparing children with DS to their peers.

In the present study, $26.6 \%$ of children with DS were underweight, $72.8 \%$ attained normal weight for age when plotted on DS growth charts. This was different from the study by Osaili et $\mathrm{al}^{32}$ who found that only $7.7 \%$ were underweight in relation to DS charts. However, Senna Rodrigues et $\mathrm{al}^{33}$ found that $30 \%$ of DS participants were underweight. This may be explained by history of repeated hospitalization, ICU admissions, CHD, and respiratory infections among our study population.

The overall prevalence of $\mathrm{CHD}$ in this study was $40 \%$ which is higher than general population prevalence that is estimated as 3.5 to 17.5 per 1,000 live births. ${ }^{34}$ This is in agreement with previous studies in Egypt, in which the prevalence of CHD ranged from 36.9 to $43.9 \%{ }^{35-37}$ In Saudi Arabia rates ranged from 40.9 to $61.3 \%$ according to. ${ }^{38-40}$ Recently rates in other countries as Libya, Sudan, and Iran were $45,43.1$, and $50 \%$, respectively ${ }^{41-43}$ Rates from other countries ranged from 43 to $58 \% .{ }^{44,45}$ Variations in CHD prevalence in DS cases could be explained by many screening programs, diagnostic facility, genetic, socioeconomic, and environmental variability of different study populations. ${ }^{37}$

Regarding the pattern of CHD, single anomalies were more prevalent than combined CHD, represented by 78 patients (27\%). This was in agreement with Bergström et al, ${ }^{45}$ who noted that complex CHD became less prevalent in infants of DS, which might be related to selective abortion of fetuses with DS or improving in antenatal diagnosis of complex CHD.
In our study, the most observed CHD patterns were ASD, PDA, and VSD with prevalence rates 10.7, 7.1, and 4.2\%, respectively. El-Gilany et $\mathrm{al}^{37}$ reported that VSD, AVSD, and ASD were most frequently observed as isolated CHD. Afifi et $\mathrm{al}^{35}$ found that VSD, ASD, PDA, and AVSD were the most frequent. Mokhtar and Abdel-Fattah ${ }^{46}$ reported AVSD and ASD were the commonest. The commonest CHD in DS in European countries and United States were endocardial cushion defects (43\%), resulting in AVSD/AV canal defect, VSD, and ASD secundum. ${ }^{47,48}$ In Asia, isolated VSD was the commonest defect $(40 \%)^{49}$; however, in Latin America, ASD secundum was suggested to be the commonest lesion. ${ }^{50}$

Children with DS have increased prevalence of autoimmune disorders, and higher prevalence of thyroid diseases with lifetime prevalence range 13 to $63 \%{ }^{51}$ In our study, $12.1 \%$ of children with DS had thyroid dysfunction, which is higher than the incidence of thyroid dysfunction previously reported in African children $(0.13 \%){ }^{52}$ Wide quoted ranges of thyroid dysfunctions in DS might be explained by different definitions in laboratory techniques or population identifications. $^{53}$

\section{Conclusion}

Comorbidities such as CHD, thyroid dysfunction, hospitalization and ICU admissions, and global developmental delay were prevalent in DS. CHD was the most common comorbidity; among these, ASD, PDA, and VSD were the commonest. Among studied dysmorphic features, upward slanting palpebral fissures was the most frequent feature. Risk factors as 
advanced parental age, low socioeconomic status, parental education, rural residence, and limited access or improper prenatal scanning may play a role in DS. However, control group and larger sample size are needed for more significant conclusions. Other limitations of the study were the absence of data regarding prenatal screening and the inclusion of ultrasound scan alone. Identification of DS with comorbidities allows them to obtain appropriate therapeutic and educational interventions.

\section{Ethical Approval}

Ethical approval from Ethical Committee, Faculty of Medicine, Cairo University was received prior to commencement of the study (approval number: I-250218). Informed consent was obtained from the participant's caregivers, and they were assured of confidentiality. The purpose of this study was explained to them in simple clear language and their rights to terminate their participation, without affecting care and services offered to their children was assured.

\section{Funding}

None.

\section{Conflict of Interest}

None declared.

\section{Acknowledgments}

The authors thank Clinical Genetics clinic, Cairo University Children Hospitals, all patients included, and their families for participating in the study.

\section{References}

1 Benhaourech S, Drighil A, Hammiri AE. Congenital heart disease and Down syndrome: various aspects of a confirmed association. Cardiovasc J Afr 2016;27(05):287-290

2 Vacca RA, Bawari S, Valenti D, et al. Down syndrome: neurobiological alterations and therapeutic targets. Neurosci Biobehav Rev 2019;98:234-255

3 Alsubie HS, Rosen D. The evaluation and management of respiratory disease in children with Down syndrome (DS). Paediatr Respir Rev 2018;26:49-54

4 Abou-Youssef HS, Kamal MM, Mehaney DA. Triple test screening for Down syndrome: an Egyptian-tailored study. PLoS One 2014;9 (10):e110370

5 Bittles AH, Glasson EJ. Clinical, social, and ethical implications of changing life expectancy in Down syndrome. Dev Med Child Neurol 2004;46(04):282-286

6 Perkins A. The lowdown on Down syndrome. Nurs Made Incred Easy 2017;15(02):40-46

7 Shalaby HMA. A study of new potential risk factors for Down syndrome in Upper Egypt. Egypt J Med Hum Genet 2011;12(01): 15-19

8 Diamandopoulos K, Green J. Down syndrome: an integrative review. J Neonatal Nurs 2018;24(05):235-241

9 Colvin KL, Yeager ME. What people with Down Syndrome can teach us about cardiopulmonary disease. Eur Respir Rev 2017;26 (143): 160098

10 Carfi A, Antocicco M, Brandi V, et al. Characteristics of adults with Down syndrome: prevalence of age-related conditions. Front Med (Lausanne) 2014;1:51
11 Stefanidis K, Belitsos P, Fotinos A, Makris N, Loutradis D, Antsaklis A. Causes of infertility in men with Down syndrome. Andrologia 2011;43(05):353-357

12 Davis MAC, Spriggs A, Rodgers A, Campbell J. The effects of a peerdelivered social skills intervention for adults with comorbid down syndrome and autism spectrum disorder. J Autism Dev Disord 2018;48(06):1869-1885

13 Sullivan KD, Evans D, Pandey A, et al. Trisomy 21 causes changes in the circulating proteome indicative of chronic autoinflammation. Sci Rep 2017;7(01):14818

14 El-Gilany A, El-Wehady A, El-Wasify M. Updating and validation of the socioeconomic status scale for health research in Egypt. East Mediterr Health J 2012;18(09):962-968

15 Zemel BS, Pipan M, Stallings VA, et al. Growth Charts for Children With Down Syndrome in the United States. Pediatrics 2015;136 (05):e1204-e1211

16 CDC. Growth charts-clinical growth charts. Published online 2000. Accessed 15 march 2021 at: https://www.cdc.gov/growthcharts/clinical_charts.Htm

17 Feigelman S. The second year. Nelson Textbook Pediatrics. 20th ed. Philadelphia, PA: Elsevier; 2016

18 Khoshnood B, Wall S, Pryde P, Lee KS. Maternal education modifies the age-related increase in the birth prevalence of Down syndrome. Prenat Diagn 2004;24(02):79-82

19 Dzurova D, Pikhart H. Down syndrome, paternal age and education: comparison of California and the Czech Republic. BMC Public Health 2005;5(01):69

20 Vashist M, Kumar A. Whether paternal age effect exists as a risk factor in trisomy 21. Biosci Biotechnol Res Asia 2016;8(01): 247-252

21 Oldereid NB, Wennerholm U-B, Pinborg A, et al. The effect of paternal factors on perinatal and paediatric outcomes: a systematic review and meta-analysis. Hum Reprod Update 2018;24(03): 320-389

22 Fisch H, Hyun G, Golden R, Hensle TW, Olsson CA, Liberson GL. The influence of paternal age on down syndrome. J Urol 2003;169 (06):2275-2278

23 Thompson JA. Disentangling the roles of maternal and paternal age on birth prevalence of down syndrome and other chromosomal disorders using a Bayesian modeling approach. BMC Med Res Methodol 2019;19(01):82

24 Kava MP, Tullu MS, Muranjan MN, Girisha KM. Down syndrome: clinical profile from India. Arch Med Res 2004;35(01):31-35

25 Azman BZ, Ankathil R, Siti Mariam I, et al. Cytogenetic and clinical profile of Down syndrome in Northeast Malaysia. Singapore Med J 2007;48(06):550-554

26 Mokhtar MM, Abdel Aziz AM, Nazmy NA, Mahrous HS. Cytogenetic profile of Down syndrome in Alexandria, Egypt. EMHJ - East Mediterr Health J 9 1-2 37-44 2003. Published online 2003. Accessed 2003 at: https://apps.who.int/iris/handle/10665/ 119241

27 Ahmed I, Ghafoor T, Samore NA, Chattha MN. Down syndrome: clinical and cytogenetic analysis. J Coll Physicians Surg Pak 2005; 15(07):426-429

28 Speed RM, Johnston AW, Evans HJ. Chromosome survey of total population of mentally subnormal in North-East of Scotland. J Med Genet 1976;13(04):295-306

29 Patterson T, Rapsey CM, Glue P. Systematic review of cognitive development across childhood in Down syndrome: implications for treatment interventions. J Intellect Disabil Res 2013;57(04): 306-318

30 Aoki S, Yamauchi Y, Hashimoto K. Developmental trend of children with Down syndrome - How do sex and neonatal conditions influence their developmental patterns? Brain Dev 2018;40(03): 181-187

31 Keusch GT. The history of nutrition: malnutrition, infection and immunity. J Nutr 2003;133(01):336S-340S 
32 Osaili TM, Attlee A, Naveed H, et al. Physical status and parentchild feeding behaviours in children and adolescents with Down syndrome in the United Arab Emirates. Int J Environ Res Public Health 2019;16(13):E2264

33 Senna Rodrigues B, Campos Pellanda L, Andreatta Gottschall CB. Nutritional assessment of children and teenagers with Down syndrome and congenital cardiopathy. Rev Chil Nutr 2012;39 (02):151-158

34 Bolisetty S, Daftary A, Ewald D, Knight B, Wheaton G. Congenital heart defects in Central Australia. Med J Aust 2004;180(12):614-617

35 Afifi HH, Abdel Azeem AA, El-Bassyouni HT, Gheith ME, Rizk A, Bateman JB. Distinct ocular expression in infants and children with Down syndrome in Cairo, Egypt: myopia and heart disease. JAMA Ophthalmol 2013;131(08):1057-1066

36 Tosson A, Amr K, Taher M. Polymorphisms in folate-metabolizing genes as risk factors for congenital heart defects in Down syndrome in Egypt. Int J Biomed Res 2015;6(12):963-966

37 El-Gilany A-H, Yahia S, Wahba Y. Prevalence of congenital heart diseases in children with Down syndrome in Mansoura, Egypt: a retrospective descriptive study. Ann Saudi Med 2017;37(05):386-392

38 Abbag FI. Congenital heart diseases and other major anomalies in patients with Down syndrome. Saudi Med J 2006;27(02):219-222

39 El-Attar L. Congenital heart diseases in Saudi Down syndrome children: frequency and patterns in Almadinah Region. Res J Cardiol 2015;8(01):20-26

40 Morsy MM, Algrigri OO, Salem SS, et al. The spectrum of congenital heart diseases in down syndrome. A retrospective study from Northwest Saudi Arabia. Saudi Med J 2016;37(07):767-772

41 Elmagrpy Z, Rayani A, Shah A, Habas E, Aburawi EH. Down syndrome and congenital heart disease: why the regional difference as observed in the Libyan experience? Cardiovasc J Afr 2011; 22(06):306-309

42 El-Shazali O, Ahmed H, El-Shazali $\mathrm{H}$. The spectrum of congenital heart defects in infants with Down's syndrome, Khartoum, Sudan. J Pediatr Neonatal Care 2015;2(05):00091
43 Poursadegh Zonouzi AA, Ahangari N, Rajai S, Poursadegh Zonouzi A, Akbarzadeh Laleh M, Nejatizadeh A. Congenital heart defects among Down syndrome patients: a clinical profiling. J Public Health 2016;24(01):57-63

44 Kim M-A, Lee YS, Yee NH, Choi JS, Choi JY, Seo K. Prevalence of congenital heart defects associated with Down syndrome in Korea. J Korean Med Sci 2014;29(11):1544-1549

45 Bergström S, Carr H, Petersson G, et al. Trends in congenital heart defects in infants with Down Syndrome. Pediatrics 2016;138(01): e20160123-e20160123

46 Mokhtar MM, Abdel-Fattah M. Major birth defects among infants with Down's syndrome in Alexandria, Egypt (1995-2000). J Trop Pediatr 2002;48(04):247-249

47 Freeman SB, Taft LF, Dooley KJ, et al. Population-based study of congenital heart defects in Down syndrome. Am J Med Genet 1998;80(03):213-217

48 Vis JC, Duffels MGJ, Winter MM, et al. Down syndrome: a cardiovascular perspective. J Intellect Disabil Res 2009;53(05): 419-425

49 Jacobs EGJ, Leung MP, Karlberg J. Distribution of symptomatic congenital heart disease in Hong Kong. Pediatr Cardiol 2000;21 (02):148-157

50 Vida VL, Barnoya J, Larrazabal LA, Gaitan G, de Maria Garcia F, Castañeda AR. Congenital cardiac disease in children with Down's syndrome in Guatemala. Cardiol Young 2005;15(03):286-290

51 Hardy O, Worley G, Lee MM, et al. Hypothyroidism in Down syndrome: screening guidelines and testing methodology. Am J Med Genet A 2004;124A(04):436-437

52 Oyenusi EE, Ajayi EO, Akeredolu FD, Oduwole AO. Pattern of thyroid disorders in children and adolescents seen at the Lagos University Teaching Hospital, Nigeria, over a 10 -year period. Niger Med J 2017;58(03):101-106

53 Gibson PA, Newton RW, Selby K, Price DA, Leyland K, Addison GM. Longitudinal study of thyroid function in Down's syndrome in the first two decades. Arch Dis Child 2005;90(06):574-578 